\title{
Investigation of the influence of hollow aluminosilicate microspheres on properties of elastomer fire- thermal protective coatings
}

\author{
Victor F. Kablov', Oxana M. Novopol'tseva ${ }^{1}$, and Vladimir G. Kochetkov,"* \\ ${ }^{1}$ Volzhsky Polytechnical Institute (branch) VSTU, 404121, 42a Engelsa Street, Volzhsky, Russia
}

\begin{abstract}
The paper considers the influence of the introduction of aluminosilicate microspheres on value of the Payne effect, rheometric, physico-mechanical thermophysical and fire-heat-shielding properties of the elastomer compositions used in the thermal protective coatings based on ethylene-propylene rubber. It was found that partial sorption of vulcanization accelerators and sulfur can occur on the surface of microspheres, followed by their desorption at the vulcanization temperature. This is confirmed by the appearance of a second peak on the vulcanization rate curve. The use of hollow aluminosilicate microspheres in the composition of elastomeric fire-heat-shielding coatings makes it possible to increase the efficiency of these compositions by reducing the thermal conductivity and density of the article while saving the optimum level of physico-mechanical properties. In accordance with the proposed mechanism for the interaction of the polymer matrix and microspheres, additional crosslinked structures are formed within the rubber matrix. An increase in the content of microspheres leads to an increase in the filler-filler interaction, which leads to a relative increase in thermal conductivity. However, the thermal conductivity of compositions containing relatively large amounts of the microspheres is still lower than that of the control. The introduction of microspheres slows down the heating of the sample during high-temperature tests, while reducing the loss of mass and the rate of linear combustion.
\end{abstract}

\section{Introduction}

Processes of filler-filler and elastomer-filler interactions are an important characteristic for the elastomer compositions working in dynamic conditions. Typically, filler-filler interactions or the formation of spatial grid is estimated by volume of Payne effect, i.e. reduction dynamic elastic modulus at low strain and increasing dynamic elastic modulus at high deformation. The value of Payne effect correlates with the dispersion degree of the active filler agglomerates and the quantity of maximum deformation per cycle - with material viscosity at the beginning of loading, and thereby a peak load (e.g., at the time of loading rollers).

When creating a fire and thermal protection materials increase the interaction of the filler-filler is not uniquely negative. At an acceptable reduction of physical and mechanical properties increase interaction filler-filler promotes the formation of additional spatial crosslinks exerting a reinforcing effect in the coke layer under conditions ablation erosion and breaking of the material the high velocity gas stream.

The purpose of the research is the investigation of the he influence of the introduction of aluminosilicate microspheres on value of the Payne effect, rheometric, physico-mechanical thermophysical and fire-heatshielding properties of the elastomer compositions used in the thermal protective coatings based on ethylenepropylene rubber.

\section{The experimental part}

There were investigated the influence the introduction of aluminosilicate microspheres (MFS) on Payne effect in rubber based on ethylene-propylene caoutchouc containing 30 parts by weight filler (BS-120) and sulfuric curatives. The impact of the microspheres content on physical and mechanical characteristics of the elastomer composition and the Paine effect are presented in Table 1.

A study of the rheometric characteristics (MDR 3000 Professional, ASTMD2084-79) has shown that kinetic curves of vulcanization of samples containing small dosages of MSF (1-3 parts by weight) have flexures characteristic of two-stage vulcanization, which is confirmed by the appearance of a second peak on the vulcanization rate curve (Fig. 1).

This feature of the kinetics of vulcanization can be explained as a partial sorption of the sulfur and vulcanization accelerators by the surface of the microspheres, and followed their desorption at the vulcanization temperature, and by the flow of additional structuring processes (Fig. 2).

\footnotetext{
*orresponding author: geminy-i@mail.ru
} 


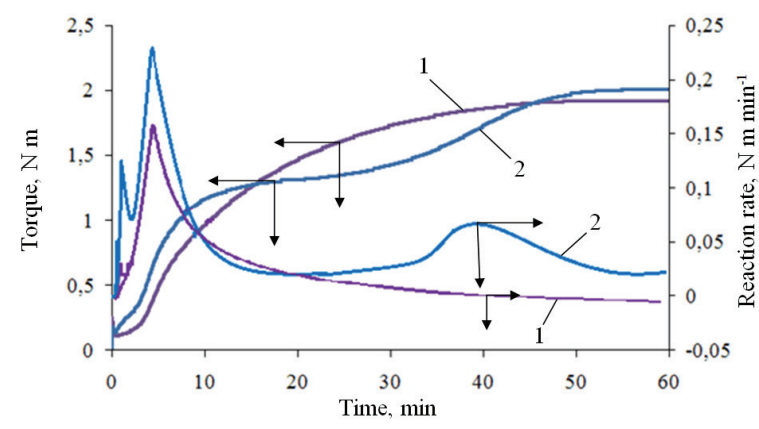

Fig. 1. Kinetic curves of vulcanization and reaction rate curves of the control mixture (1) and a mixture containing 1 wt. MFS (2)
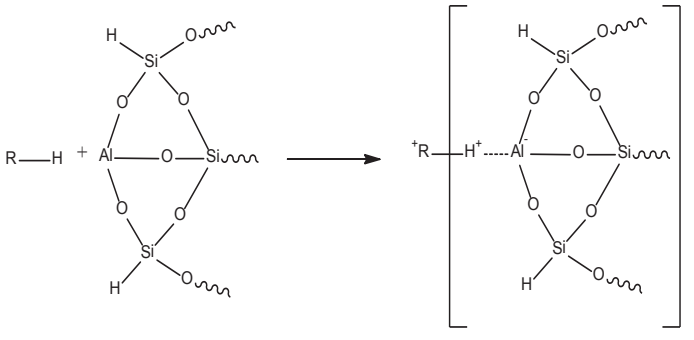

Fig. 2. The proposed scheme of interaction between the MFS and elastomer matrix

The microsphere surface is coated with the network of hydroxyl ions, which are responsible for the adsorption properties of aluminosilicates. Some authors, taking into account possible coordination bond at the Al atom in aluminosilicates, consider the aluminum atom with coordination number 3 as the active site. Upon interaction of macromolecules that form a carbocation with aluminosilicate, the coordination number of the aluminum atom becomes equal to 4 [7, 8] (fig. 2). The progress of such processes is also indicated by an increase in the Payne effect characterizing the degree of interaction of polymer-polymer, filler-filler and polymerfiller and decrease in swelling in toluene.

Fig. 3 shows the dependence of the elastic component of the shear modulus $\left(\Delta \mathrm{G}^{\prime}\right)$ of the strain amplitude for the test compositions.

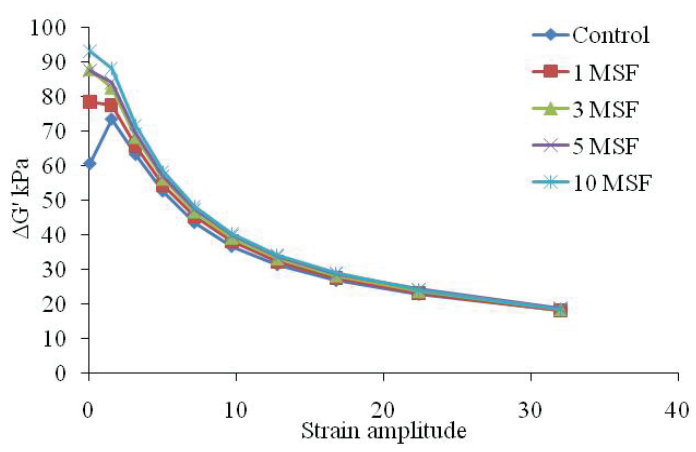

Fig. 3. The dependence of the elastic component of the shear modulus $\left(\Delta G^{\prime}\right)$ of the strain amplitude
Table 1. The impact of the microspheres content on Paine effect, rheological and physico-mechanical characteristics of the elastomer composition.

\begin{tabular}{|c|c|c|c|c|c|}
\hline \multirow{2}{*}{ Parameter } & \multicolumn{5}{|c|}{$\begin{array}{l}\text { MSP content, wt parts per } 100 \text { wt parts of } \\
\text { rubber }\end{array}$} \\
\hline & $\begin{array}{l}\text { control } \\
\text { sample }\end{array}$ & 1 & 3 & 5 & 10 \\
\hline \multicolumn{6}{|c|}{ Vulcanization characteristics of rubber stocks at $165^{\circ} \mathrm{C}$} \\
\hline $\begin{array}{c}\mathrm{M}_{\min }- \\
\text { minimal } \\
\text { torque, } \mathrm{N} \mathrm{m}\end{array}$ & 0,11 & 0,13 & 0,14 & 0,14 & 0,14 \\
\hline $\begin{array}{c}\mathrm{M}_{\max }- \\
\text { maximal } \\
\text { torque, } \mathrm{N} \mathrm{m}\end{array}$ & 1,92 & 2,13 & 2,19 & 2,01 & 1,97 \\
\hline $\begin{array}{c}\tau_{\mathrm{S}}- \\
\text { induction } \\
\text { period, min }\end{array}$ & 3,81 & 2,88 & 2,83 & 2,55 & 2,49 \\
\hline $\begin{array}{c}\mathrm{R}_{\mathrm{v}}- \\
\text { vulcanization } \\
\text { rate, } \text { min }^{-1}\end{array}$ & 4,29 & 4,33 & 3,71 & 3,92 & 4,01 \\
\hline $\begin{array}{l}\Delta \mathrm{G}^{\prime} \text { - Payne } \\
\text { effect }\end{array}$ & 55,37 & 59,44 & 64,22 & 65,29 & 69,74 \\
\hline
\end{tabular}

Properties of vulcanizates (vulcanization at $165^{\circ} \mathrm{C}, 60 \mathrm{~min}$ )

\begin{tabular}{|c|c|c|c|c|c|}
\hline $\begin{array}{c}f_{t} \text { - nominal } \\
\text { tensile } \\
\text { strength, } \\
\mathrm{MPa}\end{array}$ & 10,3 & 12,9 & 12,1 & 10,9 & 9,4 \\
\hline $\begin{array}{c}\text { Erel - relative } \\
\text { elongation at } \\
\text { break, \% }\end{array}$ & 643 & 650 & 530 & 500 & 480 \\
\hline $\begin{array}{c}\theta_{\text {res }}- \\
\text { relative } \\
\text { elongation } \\
\text { set, \% }\end{array}$ & 20 & 20 & 20 & 16 & 16 \\
\hline $\begin{array}{c}\rho-\text { density, } \\
\text { kg m-3 }\end{array}$ & 1060 & 1025 & 1014 & 1006 & 998 \\
\hline $\begin{array}{c}w-\text { degree } \\
\text { of swelling } \\
\text { in toluene, \% }\end{array}$ & 264 & 243 & 219 & 184 & 175 \\
\hline Cages in & & & & \\
\hline
\end{tabular}

Changes in vulcanizate properties after aging in $\operatorname{air}\left(125^{\circ} \mathrm{C}, 72 \mathrm{~h}\right)$

\begin{tabular}{|c|c|c|c|c|c|}
\hline $\begin{array}{c}\Delta f_{t}-\text { relative } \\
\text { changes after } \\
\text { aging, \% }\end{array}$ & $-35,1$ & $-32,7$ & $-33,5$ & $-36,2$ & $-36,9$ \\
\hline $\begin{array}{c}\Delta \varepsilon_{\text {rel }}- \\
\text { relative } \\
\text { changes after } \\
\text { aging, \% }\end{array}$ & $-40,5$ & $-39,7$ & $-40,2$ & $-41,2$ & $-42,0$ \\
\hline \multicolumn{2}{|c|}{ Heat-protecting and thermal properties of vulcanizates } \\
\hline $\begin{array}{c}\tau_{T \rightarrow 100} \text { oC }- \\
\text { warmed up } \\
\text { to } 100^{\circ} \mathrm{C} \\
\text { time, } \mathrm{s}\end{array}$ & 200 & 270 & 280 & 320 & 330 \\
\hline $\begin{array}{c}\Delta m-\mathrm{sample} \\
\text { weight loss } \\
\text { in the course } \\
\text { of the test, \% }\end{array}$ & 28,78 & 17,87 & 17,15 & 15,38 & 16,25 \\
\hline $\begin{array}{c}V_{\text {l.c. }}-\text { linear } \\
\text { combustion } \\
\text { velocity, mm } \\
\mathrm{s}^{-1}\end{array}$ & 24,12 & 23,01 & 21,42 & 20,87 & 20,08 \\
\hline $\begin{array}{c}\mathrm{C}_{\mathrm{m}}-\text { heat } \\
\text { capacity, W } \\
\mathrm{m}^{-1} \mathrm{~K}^{-1}\end{array}$ & 1635 & 1641 & 1631 & 1621 & 1619 \\
\hline $\begin{array}{c}\lambda- \\
\text { conductivity, } \\
\mathrm{J} \mathrm{kg}^{-1} \mathrm{~K}^{-1}\end{array}$ & 0,23 & 0,19 & 0,19 & 0,20 & 0,21 \\
\hline
\end{tabular}


It follows from the above data, the increased content of MSF leads to increase Payne effect by $20-30 \%$, which indicates an increase in the filler-filler interactions in the rubber matrix. The constant value of the elastic component of the shear modulus for large deformation, demonstrates consistency in the contribution of the hydrodynamic effect module, polymer-filler interaction and "structure inside the rubber" [5].

The data in Table 1 show that the introduction of MSF allows increase conditional tensile strength by $20-$ $40 \%$.

Thus, an increase in tensile strength conditional on introducing $1 \mathrm{wt}$ part of microspheres may be due to the formation of additional adsorption bonds. The occurrence of such processes is also suggested by a decrease in the sample swelling.

However, upon further increase microsphere content conventional tensile strength is decreased that is apparently due to a decrease of rubber homogeneity.

To evaluate the flame and heat resistance of the samples, we determined the following parameters using the developed procedure: dependence of the temperature on the unheated sample surface on the time of the action of open fl ame from a plasma torch, the sample weight loss, and the linear combustion velocity.

In high-temperature heating, the temperature created on the sample surface was of the order of $2000{ }^{\circ} \mathrm{C}$.

Introduction of microspheres decelerates the speed of the sample heating in high-temperature tests (Fig. 4).

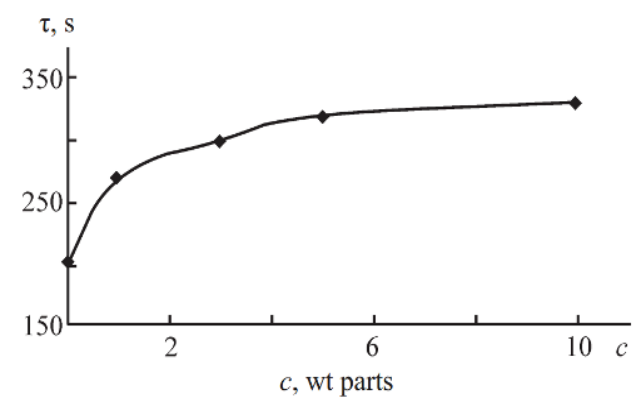

Fig. 4. Time $\tau$ in which the unheated sample surface is warmed up to $100^{\circ} \mathrm{C}$ as a function of the microsphere content $\mathrm{c}$.

Owing to the occurrence of additional cross-linking processes in the coking layer of samples containing microspheres, the time in which the unheated surface of the sample is warmed up to $100{ }^{\circ} \mathrm{C}$ increases (by 35$65 \%$ ), and the weight loss and linear combustion velocity decrease.

The forming coke structure is more uniform, and the pore diameter in it is smaller than in the control sample. The mean pore diameter in the prepyrolysis zone decreases from 350-420 to 110-120 $\mu \mathrm{m}$ (Figs. 5, 6).

Introduction of microspheres leads to a 10-20\% decrease in the thermal conductivity of the elastomer compound. An increase in the content of the microspheres can lead to the formation of "thermal conductivity bridges" due to enhancement of the fi llerfi ller interaction (20-30\% increase in the Payne effect), which, in turn, leads to a relative increase in the thermal conductivity.
However, even at the MSP content increased to $10 \mathrm{wt}$ parts, the thermal conductivity of the compound remains lower than that of the control sample.
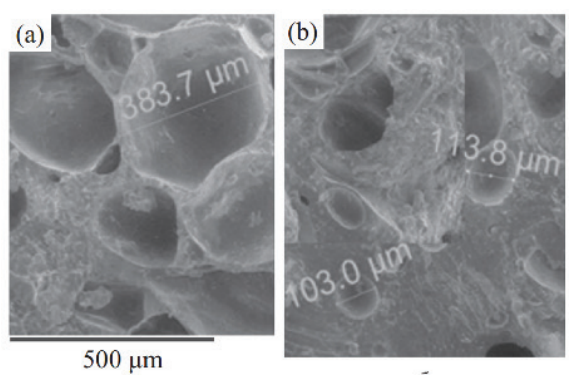

Fig. 5. Structure of the prepyrolysis layer of the samples after the test. Control sample (a) and sample containing $5 \mathrm{wt}$ parts of MSF (b).

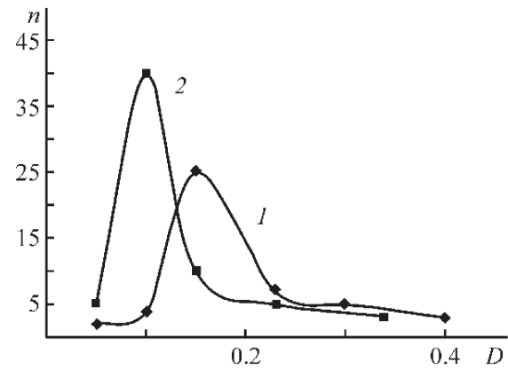

Fig. 6. Pore diameter distribution in the prepyrolysis layer of the samples. Relative amount of pores (n) and pore diameter (D). Control sample (1) and sample containing 5 wt parts of MSF (2).

\section{Conclusions}

The use of hollow aluminosilicate microspheres as components of elastomer flame-retardant and heatprotecting materials enhances the performance of these compounds owing to a decrease in the thermal conductivity and density of the item, with the optimum level of physicomechanical properties preserved. In accordance with the suggested mechanism of interaction of the polymer matrix and microspheres, additional crosslinked structures within the rubber matrix are formed. An increase in the content of microspheres leads to enhancement of the filler-filler interaction. Constant value of the elastic constituent of the shear modulus at high strains demonstrates the constancy of the contribution made to the modulus by the hydrodynamic effect, polymer-filer interaction, and "structure within the rubber." Hence, optimum choice of the rubber to microspheres ratio allows formation of additional crosslinked structures within the elastomer matrix, favoring manifestation of the reinforcing effect in the coke layer of the material under the conditions of erosion removal and detachment of the material with a high-velocity gas flow. Introduction of microspheres favors formation of a more regular dense finely porous coke structure upon high-temperature treatment, which, in turn, leads to an increase in the time in which the unheated surface of the sample is warmed up to $100^{\circ} \mathrm{C}$ and to a decrease in the weight loss and linear combustion velocity. 
The work was carried out with the financial support of the Ministry of Education and Science of the Russian Federation in the framework of the basic part of the state assignment for 2017-2019. (Project 4.7491.2017 / CU) on equipment purchased under the Strategic Development Program of Volgograd State Technical University for 2012-2016.

\section{References}

1. G.E. Zaikov, E.V. Kalugina, and K.Z. Gumargalieva Fundamental regularities of thermal oxidation of heatresistant heterochain polymers, Thermal Stability of Engineering Heterochain Thermoresistant Polymers, Utrecht: 280 p. (2004)

2. RF Patent 2552728, Publ. 2015.

3. RF Patent 2473751, Publ. 2013.

4. A.S. Inozemtsev, and E.V. Korolev, Promyshl. Grazhd. Stroit., 10, pp. 80-83 (2013)

5. RF Patent 2473504, Publ. 2013.

6. K.L. Kandyrin, and A.S. Sedov, Vopr. Prakt. Tekhnol. Izgot. Shin, 1 (50), pp. 93-100 (2010).

7. J.E. Huheey, Inorganic Chemistry: Principles of Structure and Reactivity, New York: Harper \& Row, 3rd ed (1983)

8. M.M. Shul'ts, Soros. Obraz. Zh., 8, pp. 25-38 (1997) 